\title{
The ethical orientations of education as a practice in its own right
}

\author{
Pádraig Hogan* \\ Education Department, National University of Ireland, Maynooth, Ireland
}

\begin{abstract}
This article is the second of a two-part investigation, the first part of which was published in Ethics and Education, vol. 5, issue 2, 2010, under the title 'Preface to an ethics of education as a practice in its own right'. Although it builds on the arguments of that 'preface', this second part of the investigation can be read as a stand-alone essay. It begins with a brief review of a new subordination of educational practice achieved by a neoliberal tenor in international educational reforms in recent decades in Western societies. The practical context for the essay however is that failure of many of these reforms, like the failure of neo-liberal dominance in socioeconomic policy, has given rise to emergent opportunities where inspirations for educational debate and policy-making are concerned. Arguing for the uptake of such opportunity, the ethical tenor of education as a practice in its own right is explored under four headings: (1) review and clarification of the inherent purposes of education as a practice; (2) investigation of educationally productive pathways that are characteristic of education as a practice in its own right; (3) elucidation of a recognisable family of virtues that arise from that practice itself; (4) exploration of the kinds of relationships through which these virtues, and their educational fruits, are nourished.
\end{abstract}

Keywords: educational practice; inherent purposes; virtues of teaching; virtues of learning; educational ethics; relationships of learning

\section{Introduction: Control, reform and emergent opportunity}

To call something a practice in its own right suggests, at first sight, that there is a body of authoritative knowledge that identifies both the goals of the practice and the procedures to be applied to achieve these goals. This body of authoritative knowledge is frequently called 'the scientific base' of a practice. It is essentially what enables a practice to enjoy a claim to autonomy in the conduct of its affairs, including the research activities that develop and enhance the practice. Even a glance at the history of education, however, is enough to show that education does not readily fit the picture just drawn. In the first place, there has been little in the way of autonomy granted to education as a practice, especially when compared to practices like law, medicine or engineering. Throughout most of its long history, education at least in Western civilisation - has been predominantly controlled by the Christian Church as an institution; and by the denominational churches after the Reformation. Certain forms of teaching and learning were prescribed, and others proscribed.

\footnotetext{
*Email: padraig.hogan@nuim.ie 
The former received their basic character and orientation from ecclesiastical authorities. In the wake of the Enlightenment and the Industrial, American and French Revolutions, church control of education was increasingly challenged in Western countries. These modernising efforts were, however, rarely undertaken to advance education as a practice in its own right, notwithstanding their progressive expansion of schooling from a concern of a minority to a mandatory requirement for all children. Indeed, both older and newer contesting parties characteristically acquiesced in the view that education was fundamentally something to be controlled and steered from above by institutionalised interests. The depiction of education as a 'contested' arena remains a familiar one, not least in critical educational research literature, and it tends to obscure this shared presupposition. ${ }^{1}$ This depiction also discloses human agency in education as something that is more responsive to extrinsic forces than to inherently educational purposes.

In any case, something as momentous as another Reformation, this time of a more secular kind, occurred in most Western educational systems in the past two decades. Here, the increasing scope for the exercise of professional discretion that the conduct of public education had been gaining in many countries from the midtwentieth century onwards was decisively reversed. In thrall to a neo-liberal orthodoxy championed in particular by the Thatcher and Reagan administrations, governments and their agents assumed powers over education that were no less comprehensive than those secured by their ecclesiastical predecessors in earlier centuries. Control was now to be enforced through the threat of withdrawal of funds, as distinct from the more historic prerogatives of church authorities in appointing, promoting and dismissing teachers.

The fact that such a large-scale colonisation of education could be accomplished in such a short time - effectively from the late 1980s to the turn of the century reveals an uncomfortable truth for education vis-à-vis other professional practices. Unlike law, for instance, there was no clearly acknowledged tradition of separation of powers between government and education. Unlike medicine and engineering, education was seen to lack the complex scientific base on which professional expertise usually builds its claim to autonomy. More significantly perhaps, though this is a long story that cannot be told here, education as a practice lacked a robust sense of its own professional identity. In short, the intellectual resources available to the professional leadership of education - including the teaching profession and the educational research community - were no match for the concentrated ideological energies of the reformers.

Among the more notable consequences of a generation of international educational reforms are the three following ones. First, an unprecedented performance-management machinery to enforce compliance marks a new form of colonisation and a new era of subordination of education as a practice. Second, the recasting of issues of quality in educational experience as issues of indexed quantity (of grades, test scores, etc.) pushes the heart of educational quality itself to the margins, or even out of the picture. In doing so, it also neglects the question of equity in educational opportunity. Third, where the moral tenor of officially approved practice is concerned, pride of place is effectively given to a mercenary ethic, one which extends its own control and influence through a large-scale individualisation of rewards. 
Yet, it would be a mistake to view post-reform education in the early twenty-first century as a conquered arena of endeavour. That the reforms have frequently failed to meet the expectations of their leading protagonists has been acknowledged by some of these protagonists themselves. Chris Woodhead, for instance, former Chief Inspector of Schools in England during most of the 1990s, and an ideologue of the neo-liberal reform movement, declared in August 2009 that in practice, the reforms had 'done more harm than good'. 'At an international level, emphatic voices that proclaimed the failure of schools and colleges in the 1980s and $1990 \mathrm{~s}^{3}$ have become somewhat equivocal, in the face of the unspectacular fruits of their own remedies. Although partisans of a coercive stance towards schools are still around, a more urbane international discourse on education has been noticeably on the rise, seeking to bridge the gap between educational research and policymaking. In the Anglophone world, this ascendant discourse is focused largely on educational leadership and management. Key themes in its extensive literature range from the cultivation of collaborative professional cultures in schools to the macro-management of education as a strategic resource for competitiveness in a globalised world.

Sections of this research literature, notably studies that elucidate the "collaborative' end of the research spectrum, proceed on the implicit assumption that education is a practice in own right, or that it least has claims to a qualified professional autonomy. Representative examples of this literature include: from America, Sustainable Leadership (2006) by Andy Hargreaves and Dean Fink; from the UK, School Inspection and Self-evaluation (2006) by John MacBeath; from Australia, Educational Leadership: Key Challenges and Ethical Tensions (2007) by Patrick Duignan. At the more macro-management end of the spectrum lie a host of publications from bodies like the Organisation for Economic Co-operation and Development (OECD). Characteristically, these investigate and monitor education chiefly as an arm of economic and social policy in democratic countries, though usually with some recognition that education has its own inherent goals. ${ }^{4}$

The economic havoc wrought in countless countries within the last few years by the ill-fortunes of unregulated financial capitalism has added a further dimension to debates on education and its significance for individual and social wellbeing. Not only has the international economic plunge aroused massive civic anger, it has also led to a ferment of doubt in policymaking quarters. Within a newly uncertain context for policy-oriented educational research, contrary orientations are discernible. On the one hand, there are continuing efforts to progress even further with the indexing of educational achievements and to make educational research more amenable to the imperatives of performance management. ${ }^{5}$ Against this, there are questions being raised, not least in business and policymaking quarters, about the ethical vacuum at the heart of neo-liberalism, and about its assumed merits as a source of inspirations for educational policy reforms. ${ }^{6}$ Amid this ferment, there are emergent opportunities to ask anew about education as a distinctive practice, and about the ways in which this practice might best contribute not only to humanity's flourishing, but also to humanity's own survival.

The evidence is abundant that it cannot now make such contributions as the servant of a dominant mercenary credo, any more than it could previously do so as the handmaid of an institutionalised church, or of a grand political ideology. Of course, it is tempting for established powers to look the other way, or to seek 
plausible excuses, when confronted with inconvenient evidence. As the growing acrimony that accompanies G20 meetings and climate change conferences reveals, however, it is becoming increasingly difficult for governments to do so, or to pretend that business can carry on as before. In fact, if the projected population growth figures for the next half century are accurate - a global population of over 9 billion by 2050 - business simply cannot be as before, either in education or in any other area where public resources are called upon to advance a public good.

If there is any bright news for education in this ominous scenario, it lies in a challenge which is as daunting as it is worthy. That challenge is for educational practice to emerge from its historic subordination to paternalistic and bureaucratic masters, and to lay claim in an articulate and sure-footed way to its own identity as a human practice. The account that can be given of such a venture in an essay of this scope is necessarily a summary one. But within such limits, there are four key themes that can be identified for exploration, with some initial commentary on each. These four, which will be addressed in turn, are:

(1) review and clarification of the inherent purposes of education as a practice;

(2) investigation of educationally productive pathways that are characteristic of education as a practice in its own right;

(3) elucidation of a recognisable family of virtues that arise from that practice itself;

(4) exploration of the kinds of relationships through which these virtues, and their educational fruits, are nourished.

\section{The inherent purposes of education as a practice}

Few will deny that education is a value-laden undertaking. As Peters $(1966,25)$ memorably put it in his Ethics and Education, it would be a contradiction to say that a person had been educated, 'but had in no way changed for the better.' But if education is inescapably value-laden, many conclude all-too-quickly from this that the 'aims of education' must be associated with the values of particular individuals or groups. The view cited earlier, that education is an 'essentially contested' concept, is a more formal way of putting this. Or to put it more candidly: there is a multitude of educational 'philosophies' and each 'philosophy' must naturally have its own adherents and opponents. Such a conclusion obscures the very possibility that education is a practice in its own right, with its own inherent purposes and ethical commitments. Instead, it defines education from the start as a subordinate practice. The point at issue becomes clearer if we compare education with other practices like medicine and law. For instance, one hears more than occasionally of 'Catholic medical practice', or 'Islamic legal practice'. Reference to such instances illustrates that something which is normally regarded as a practice in its own right, at least in democratically constituted societies, is being subordinated from the start to the value claims of a particular group or institution. For the sake of clarity, I should add here that the subordination does not necessarily deprive the practice in question of all of its inherent purposes. Nor am I suggesting that practices can be carried on in splendid isolation from cultural circumstances. But as the arguments in the first section have pointed out, education as a practice has frequently remained 
largely subjected to such subordination long after other practices have secured the freedom to operate with an extensive measure of professional autonomy and discretion.

So much is this the case that it is necessary to ask: in a democratic society, what would an educational practice with inherent purposes of its own look like? An answer to the question might begin like this: Educational effort worthy of the name seeks to uncover those potentials that are most native to each person, and to cultivate these through practices of learning that realise the communal benefits of learning itself, not just individual benefits. To say this much may be uncontroversial, but it can still be charged that there is a vagueness here in relation to specific aims or values. On closer examination, however, it can be seen that this vagueness, if one may rightly call it that, is the necessary consequence of a corrective shift of emphasis. That shift is one away from preoccupation with the issue of whose values are to be accorded pride of place in any instance of educational practice. It marks a concentration instead on how values of any kind are to be encountered and actively engaged with in defensible practices of learning and teaching.

To argue like this is to say that a learning environment that is truly educational is marked less by allegiance to a particular party, church or group, and more by a commitment to building and sustaining a community of enquiry. It is tempting to add here that this would be enquiry 'for its own sake', but for all its distinguished Aristotelian ancestry, this phrase says too little that is illuminating in a practical sense. True, it calls attention to inherent benefits as distinct from extrinsic goals, but not to what these benefits might be; not to their genus. Probing the point further then, the inherent benefits of a community of learning become evident, in ageappropriate ways, within educational experience as it unfolds, for instance: in the unforced disclosure to learners of their own particular talents and limitations as they encounter mathematics, music, woodwork, languages and so on; in the quickening of interest provoked by finding oneself in new imaginative neighbourhoods in these and other subjects; in the new reserves of energy springing from even modest learning achievements and their affirmation; in the acknowledgement by fellow students and by a teacher of one's specific contribution to a topic being explored; and in the attentive restraint that enables one to listen to and think about the standpoints of fellow learners.

Even in this brief sample, one can discern some virtues of a non-exclusive kind (e.g. intellectual modesty, self-respect, respect for the efforts and views of others, imaginative venturing, renewal of effort) that are nurtured by communal practices of learning. Of course, one can readily envisage learning environments where virtues of a contrary kind are fostered, even unwittingly. Such environments tend to prevail where a preoccupation with extrinsic rewards or received orthodoxies neglects to perceive, or to ask, what is actually happening in educational experience as it unfolds. To argue like this is to say that the inherent purposes of learning are those that link learning itself to such non-exclusive virtues and their judicious cultivation. None of this is to deny the merits of extrinsic goals of learning, such as the provision of the occupational capabilities necessary for a society's economic advance. It is to emphasise, however, that when extrinsic goals, whether of an economic, political religious or other kind assume the upper hand, inherent purposes invariably fall victim to the forces of a macro-mobilisation. 


\section{Productive pathways for learning}

A critic who reads the preceding paragraphs might ask at this point if the fundamental values which give to any instance of education its character and direction are being set aside here in favour of values that are merely procedural. Pressing the question further, the critic might point out that education, if it is to stand for anything, must declare what philosophy of life it cherishes and seeks to advance, and what it stands against. By way of response to this plausible charge, it must be pointed out, first, that to regard education in this way is to view it primarily as a denominational kind of undertaking; denominational here is being understood not just in a religious sense, but also in a political or ideological one. Of course, it is by no means inevitable that religious denominations or political parties-in-power must view education as a vehicle for extending their own spheres of influence. But the historical record, in Western civilisations at least, shows that they find it difficult to resist doing so. In consequence, education, as a subordinate undertaking to be controlled by a political body of superiors, is taken to be part of the natural order of things. That is why I am emphasising the point that education is properly to be understood as a practice in its own right. As such a practice, in receipt of public funds, it must be accountable to the public, but accountable primarily for fruits that are of the practice itself rather than for goals imposed by church, or state or other external bodies.

Second, to regard what I have called the inherent purposes of education as more procedural than substantive in character is to misconstrue these purposes and to misunderstand at its heart education as practice. Suppose for argument's sake that human efforts at learning had secured an all-embracing account of the universe and of humankind's proper place and purpose in it, that is to say, had laid hold of final and absolute truth. In such circumstances, perhaps, a plausible case could be made for education as an auxiliary kind of techne that would enable successive generations to grasp that truth. More than a few traces of this kind of argument are to be found in the later books of Plato's Republic. ${ }^{7}$ Claims to such an all-embracing picture, held with an assured and unyielding certainty, were later to feature prominently, however, in the ways that education came for many centuries to be governed by institutionalised religions. And in the major educational reforms of more recent and more secular times, a self-assured stance of superior knowledge has been an evident characteristic of the neo-liberalism that informed much of the reform movement. Even where the ideological force of educational reform is quite mild, the picture persists of schools, colleges and universities as an available vehicle, to be steered this way or that, by the party that holds the reins of political power.

The inherent purposes of education come properly into view however, only when pretensions to final certainty and an all-embracing overview are set aside, when the limitations of even the most advanced human knowing are explicitly acknowledged. This means acknowledging, with Socrates rather than with Plato and Aristotle and their metaphysical successors, that the best achievements of human understanding are inescapably partial, and in both senses of that word: incomplete, and also burdened by bias. It means that humans would have to escape their historical and mortal state, and attain something like a God's-eye view, if incompleteness and bias were to be finally overcome. More positively, it means that a desire to detect and 
overcome biases and inadequacies should stimulate and renew human educational actions, from the questions of early childhood to those of the most advanced research. Crucially, it also means that such efforts themselves, when thoughtfully pondered, disclose an ethical standpoint that is singularly significant for educational practice. This standpoint is constituted by learning orientations that are disposed to respecting, yet also redressing, both forms of partiality. Such ethical orientations are accordingly more conversational than confrontational. They recognise that 'our ignorance expands with our knowledge': that new discoveries properly bring with them a new awareness of the immensity of what yet remains unknown. As pedagogical orientations, they promote the kinds of fluency that enable the unearthing and the asking of searching questions. But they also cultivate a discerning attentiveness to those perspectives of others that question and renew one's own best knowledge to date. The perspectives of others here must include those of the 'others' found in the subjects that come to voice in educational experience; subjects like history, art, science, literature, music, religion and so on. In short, such ethical orientations disclose distinctive and promising educational pathways by disposing human self-understanding to become venturesome and energetic, yet modest and self-critical in deliberate engagements of learning.

\section{Inherent virtues of educational practice}

Were one to remain with the inherited idea that education is a subordinate domain to those of state, church or economy, one might now adopt on behalf of 'conversation' a 'philosophical stance', like those of Platonism, Aristotelianism, Marxism, Catholicism or utilitarianism and so on. One might thus elucidate the virtues that such a stance, sometimes including influences from more than one 'ism', would expect educational practice to nourish. Such an approach is no stranger of course to the deliberations of educational professionals - in schools, in educational managements and in educational policymaking. Notwithstanding the acknowledged benefits that this well-trodden path often brings, it still gives pride of place to extrinsic purposes in educational thought and action. Likewise, the criteria of evaluation it provides are those of the 'ism' or stance in question, not criteria that are inherently educational. It is not that such extrinsic criteria are necessarily irrelevant, though where the 'ism' exercised its own power - overtly or otherwise - the cultivation of educational virtues is likely to be distorted, if not undermined. It is rather that by putting the emphasis in the wrong place they obscure the virtues that reside in educational practice itself as a distinctive domain of human experience.

Rather than being badges of one or other 'ism', inherently educational virtues are conversational ones, and for the reasons suggested in an initial way in the previous section (i.e. arising from a philosophical acknowledgement of human limitations and partialities). Exploring this 'conversational' perspective further now, it reveals that teaching and learning are misleadingly viewed as an act of transmission from teacher to student, or from an older generation to a younger one. Rather, teaching and learning comprise at a minimum an experience jointly undergone by teachers and students; undergone, however, from different cultural contexts, from different accruals of experience, from differently predisposed self-understandings. A defining 
purpose of such deliberate joint experiences is to enable various aspects of inheritances of human learning and accomplishment to evoke and cultivate a quickening of response from the differently disposed sensibilities of learners. As that response becomes more fluent and capable, questions that are progressively more critical and searching are put by students to these inheritances, to the teacher and to each other. In other words, the distinctive practice being described here seeks to enable the learners to discover in themselves and in each other, something of the historian, of the musician, of the scientist and so on; to unearth something of their sporting, artistic or spiritual aptitudes; to experience what it means to live as a genuine learner, identifying and working on one's own strengths and limitations and discovering one's emergent identity in an unforced way in a venturesome but safe community of learners.

From the teacher's side of this joint experience, the virtues called for run to a long list. Although it looks a bit schematic to provide such a list here, it is worth doing so to illustrate that the virtues spring from the conversational nature of educational practice itself, rather than from a particular 'ism' or denominational stance. Another reason for furnishing such a list of virtues is that it clearly reveals that their practical, or 'procedural' nature lacks nothing in ethical substance. So, the virtues of teaching as a practice in its own right would include:

(1) a commitment to clarity and depth of understanding in relation to the defensible purposes of teaching;

(2) the patience, perseverance and firmness necessary to draw learners, as active and responsible participants, into a vibrant learning environment;

(3) the courage, or moral energy, to put one's own truth claims at risk, to tackle challenges and obstacles and to take new pedagogical initiatives - of one's own, and with colleagues;

(4) a warm-hearted frankness, coupled with respect for each pupil's privacy and dignity;

(5) a disciplined originality which recognises that one's own knowledge is ever on-the-way, which resists the ruts of habit, and which returns ever anew to the address of the subjects that are one's abiding point of contact with the pupils;

(6) a judicious faith in pupils, even in unpromising circumstances;

(7) a setting-aside of proprietorial designs on pupils' minds and hearts, coupled with a constructive sense of self-criticism;

(8) a deep and enduring sense of care for students, recognising the claims of both equity and difference.

So much for virtues embodied in the practices of the teacher. But what about the practices of learners? The virtues we have just considered have counterparts as virtues of learning. It hardly needs to be emphasised that these also involve a personal discipline, this time on the part of learners. Three points require emphasis however. First, these virtues of learning provide the fuller context - indeed the only adequate context - in which discipline in schools is to be understood. Second, while most students may never fully measure up to their own or others' expectations in their own practice of these virtues, the virtues still provide a very valuable 
aim-in-view for teachers, students and, not least, parents. Third, as all teachers are rightly to be viewed as learners, these virtues apply to teachers as well. Characteristic virtues of learning include:

(1) a commitment to renewed effort in the pursuit of fluency, while recognising that fluency in any subject is a matter of degree, rather than a matter of something final or absolute;

(2) recognition that learning is most important as a form of enquiry and discovery, and that this calls for tolerance and active co-operation among learners, in relation to each other's attempts and contributions;

(3) a commitment to method, review and revision in one's efforts to study and understand (i.e. to pursue enquiry fruitfully);

(4) acknowledgement of the necessity for balance in the exercise of critical judgement as the fruits of learning emerge;

(5) acknowledgement of the necessity for equity where the opportunities and entitlements of all learners are concerned;

(6) receptive openness by learners to what is decently addressed to them;

(7) readiness to ask pertinent questions or raise critical queries;

(8) willingness to take responsibility for one's own learning. ${ }^{8}$

Finally, these virtues are substantive, but non-partisan. They arise from the defensible conduct of educational practice itself and they speak to the convictions of educational practitioners as practitioners - in this instance teachers. But they also allow for a wide plurality in teachers' own outlooks in matters political or religious. Their real significance lies in their embodiment in pedagogical practices more so than in whatever merits they might have as voiced aspirations. They also illustrate that the integrity of education as a practice in its own right lies as much in the insights yielded by a perceptive and ethical pedagogical thinking, such as we have been exploring here, as in any body of scientific theory. A corollary of this conclusion is that the virtues we have reviewed here are candidates for a universally defensible ethics of educational practice.

\section{Educational ethics and relationships of learning}

Virtues tend to remain aspirational or abstract unless they are embodied in actual practices. They need to be nourished through the relationships and actions that make up particular instances of a practice, or the range of practices that constitute a larger practice. Where the virtues of teaching and learning are concerned, this requires us to look more closely at the relationships through which the inherent benefits of educational practice are realised. Allowing for the wide diversity of practices - from early childhood education to adult education to postgraduate research seminars that education as a practice in its own right includes, one can distinguish four sets of relationships that characterise that larger practice. The four are: (1) the teacher's relationships to the subject or subjects being taught; (2) the teacher's relationships to the students; (3) the teacher's relationships to colleagues, to parents and guardians and to the wider public; (4) the teacher's relationship to himself/herself (i.e. the teacher's self-understanding), within which the tenor and significance of the other 
three relationships are decided. ${ }^{9}$ Clearly, each of these four could be sub-divided for further analysis. But my main purpose here is to show in outline how the interplay of these four major relationships enables us to understand from the inside the distinctive ethical orientations of educational practice and the situated nature of educational virtues.

Beginning with the first of the four relationships, what a teacher brings to an environment of learning varies decisively depending on how the teacher understands the material to be taught. For instance, the teacher might, on the one hand, regard this material as a body of knowledge and skills to be 'delivered'. It should be noted in passing that the educational reforms reviewed at the start strongly promoted a 'delivery' view of teaching, to which teachers were expected to conform. By contrast, the teacher might view the material as a range of latent voices that seek to say something; voices that need to be brought to life through the teacher's actions so that students can engage keenly and conversationally with them. Oakeshott's memorable essay 'The Voice of Poetry in the Conversation of Mankind' comes to mind here. There he depicts 'conversational' environments as places where 'thoughts of different species take wing and play around one another, responding to each other's movements and provoking one another to fresh exertions'. ${ }^{10}$ Now, it must be granted that even the most 'conversational' of teachers will regularly experience in their thoughts and actions some degree of tension between these contrasting orientations. Where the conversational orientation becomes obscured however in the teacher's relationships to the subject being taught, thoughts and experiences in learning environments are likely to remain narrowly earth-bound. In such circumstances, a teacher's ethical commitments to qualities like originality, perceptiveness of understanding and moral energy are also likely to atrophy.

The second set of relationships is the teacher's relationship to the students. Contrasting depictions of this vary from viewing it as a coercive power relationship between unequals to a form of unforced learning dialogue facilitated by the teacher as leader. ${ }^{11}$ To avoid any suggestion that the contrast here is too stark, it is worth pointing out that a teacher's relationship to students can involve both forms. It may tend at times towards dialogue, and at other times (perhaps more pressurised times) towards something more coercive or arbitrary. Few teachers would be happy to accept that the heart of their professional practice is coercive, and would be keen to draw a distinction between legitimate authority and arbitrary power. Yet, even amid the most conscientious attempts to articulate and practise the kinds of educational virtues explored in the previous section, it is difficult to rid the conduct of teaching of lapses into arbitrariness, or from work practices that embody it. And the more that teaching is officially viewed and managed as a subordinate practice, the more likely it is that arbitrary power will feature regularly in relations between teachers and students.

If the 'arbitrary power' view of the teacher-student relationship distorts it in one direction, the 'facilitation of dialogue' view distorts it in another. The problem here is not so much the issue of dialogue, though a colloquial use of the term 'dialogue', like 'conversation', can be misleading in describing relationships of teaching and learning. The more serious problem is the issue of 'facilitation'. 'Facilitation' tends to remove from the teacher the leadership 
role it apparently emphasises. Only by neglecting the teacher's relationship to the subject(s) being taught can the 'facilitation' viewpoint seriously gain purchase. Genuine leadership in building venturesome environments of learning involves something essentially more than, and different from, facilitation. It involves perceptive planning on the teacher's part to enable learners to experience new imaginative neighbourhoods - say in science, in visual arts, in geography - and to participate with increasing appetite and capability in such neighbourhoods. In addition to planning however, the practical bringing about of such experiences involves a sophisticated orchestration on the teacher's part, as well as discerning anticipation and intervention on a regular basis. The kind of dialogue appropriate to relations of teaching and learning is rarely enough that of a dialogue between friends. As the Socratic origins of a 'conversational' conception of teaching and learning shows, the teacher has already travelled many of the pathways she or he now embarks on, ever afresh, with new generations of learners. Where education is properly understood as a distinct practice with its own inherent ethics, critical reflection on this previous experience alerts the teacher to occupational hazards like pedantry or conceit. More positively, it also highlights the teacher's responsibility to both the subject and the students; a responsibility to lead a community of learners in a sure-footed, innovative, yet self-critical quest.

The third set of relationships includes the teacher's relationships to colleagues, to parents and guardians, and to the public more widely. Taking colleagues first, a conception of educational practice that does justice to its conversational core emphasises the importance of proactive colleagueship among practitioners. This is in marked contrast to the professional insulation and isolation experienced by teachers in more traditionally disposed classrooms and staffrooms. It contrasts no less with the 'contrived collegiality' which is a frequent managerialist strategy in response to officially imposed educational reforms. ${ }^{12}$ There are many aspects of collegiality that merit more extensive investigation, but in this outline I may be excused for taking a short-cut to a conclusion towards which such investigation points. That conclusion is that unless imaginative forms of collegiality are developed and regularly refined by teachers, it is difficult to see how educational practitioners can, as a body, manifest the initiative and leadership that define a practice in its own right.

Where relationships to parents are concerned, the notion that a teacher acts in loco parentis is characteristically invoked to describe this domain. Whatever its merits as a legal safeguard for both schoolchildren and their parents, from an educational perspective the concept of in loco parentis misleadingly casts teachers as stand-ins for parents. It distracts attention from the specifically educational responsibilities of teachers. Insofar as education is a practice to be distinguished from parenting, the teacher's first responsibility is to the child's progressive and healthy learning. Properly understood, this is a responsibility informed by a discerning envisaging on the teacher's part of what that child might become through sustained and fruitful experiences of learning. This envisaging, which involves a sharing of insights with parents, and increasingly with children themselves as they grow older, is to be distinguished from any fixing of the future in a rigid mould. It is ever attentive to new intimations of promise on the part of learners, and it 
recognises a responsibility to articulate that promise in suggestive but realistic ways to both students and their parents.

How teachers' relationships to the public at large are understood contrasts sharply, depending on whether education is regarded as a subordinate practice or one with its own inherent purposes. Strong versions of the subordinate view would automatically look on schools and teachers as a macro-force to carry out whatever prescription is given to them by government or its agencies. But faithfulness to inherently educational purposes does not mean that education can or should be pursued in splendid isolation from the major concerns of society and economy. What was suggested in a preliminary way earlier about teachers' responsibilities to the larger society can be put with more ethical force now. That relationship is in good order where there is a public acknowledgement of the following principle of mutual responsibilities: Where education as practice is publicly supported by the public's monies, the practice must be clearly answerable to the public for the resources and the public trust placed in it, but answerable for fruits that are of the practice itself. To those who say that this still ignores the social and economic aims of education, one might respond in the following way. Where an educational commitment to a profusion of human accomplishment properly informs and energises educational practice, the outlook is singularly promising for those capacities required for social and economic advance, and for the renewal of scientific and artistic life in society.

\section{Concluding remarks: practitioners' self-understanding}

The teacher's relationship to herself or himself is where the other three sets of relationships - to the subject(s) of study, to students, and to colleagues parents and others - come productively together. Because of its reflexive character, this relationship can also be called the teacher's self-understanding. But if there are contradictions or unaddressed tensions in this relationship, then clearly the other three relationships do not come productively together in it. Many teachers enjoy a vibrant relationship personally with the subjects they teach, yet they conduct teaching and learning chiefly in terms of 'delivery': of covering a syllabus for test or examination purposes. Other teachers might view themselves strongly as 'teachers of students, not of subjects', consequently neglecting to cultivate a relationship of continuing renewal with their subjects. Such everyday examples of contradictions and rifts in practitioners' self-understanding could be cited at length. I'm stressing them here because they tend to be prevalent in pedagogical thought and action where a professional culture is dominated by extrinsic goals, and where inherent purposes are mis-recognised or relegated. An educational ethics springing from one or other 'ism' cannot provide the resources for tackling such difficulties, or making significant inroads on them. It is also worth noting - however surprisingly- that the same remains true of an educational ethics that finds its chief orientations in one or other ethical theory; whether an ethics of duty, of justice, of utility, or other. Where the ethics of any practice in its own right are concerned, only an incisive and sympathetic grasp of the inherent purposes and predicaments of the practice itself can hope to do the work that needs to be done. 


\section{Notes}

1. Examples of this critical research literature include Schooling in Capitalist America by Bowles and Gintis (1976), and their joint article written 25 years later 'Schooling in Capitalist America Revisited' (2001) available at www.umass.edu/preferen/gintis/ soced.pdf; also Bourdieu and Passeron (1977).

2. See Woodhead's (2008) article, titled 'Chris Woodhead's part in a doomed act of education reform'.

3. Two illustrative examples are: A Nation at Risk: The Imperative for Educational Reform (1983, Washington, National Commission for Excellence in Education); Total Quality Management and the School by S. Murgatroyd and C. Morgan (1992, Buckingham Open University Press).

4. OECD (2009) gives a good overview of the OECD's work in shaping the discourse of educational policymaking, and includes an extensive bibliography of OECD publications on education from 2000 onwards.

5. An instance of the latter is the EU-funded project 'European Educational Research Quality Indicators - a cooperative research project in the 7th Framework Programme of the EU'. Details of this were made available at an invited presentation to the European Conference on Educational Research, Vienna, September 2009. See http:// www.eera-ecer.eu/ecer-programmes-and-presentations/conference/ecer-2009/network/ invited_speakers/?no_cache=1\&cHash $=$ e699b50018.

6. See for instance the EU document 'Joint progress report of the Council and the Commission on the implementation of the Education and Training 2010 work programme available at http://register.consilium.europa.eu/pdf/en/10/st05/ st05394.en10.pdf. See also the European Youth Forum's response to that report, available at http://www.esn.org/content/youth-and-meps-change-direction-eu-educationpolicy-making.

7. Plato (2007, Republic Bk 7, 518d). Whether Plato meant his observations on these points to be taken literally, or as utopian kind of satire, still remains open to debate. For instance, Karl Popper takes a literal view while Hans-Georg Gadamer argues that the ethical significance of the Republic is quite lost if the text is taken literally.

8. Both lists produced here are amended versions of material that I have been developing on for many years in work with teachers - both student teachers and experienced teachers. The first version of the lists appeared in a book of mine titled The Custody and Courtship of Experience: Western Education in Philosophical Perspective (1995).

9. This four-fold characterisation is explored in more detail in Chap. 4 of The New Significance of Learning: Imagination's Heartwork (Hogan 2009, 197).

10. Oakeshott (1962/1981) goes on to add: 'Education, properly speaking, is an initiation into the skill and partnership of this conversation in which we learn to recognize the voices, to distinguish the proper occasions of utterance, and in which we acquire the intellectual and moral habits appropriate to conversation' (199).

11. Bourdieu's and Passeron's (1977) Reproduction in Education, Society and Culture provides a good example of the first of these characterisations. Rogers' (1970) Freedom to Learn provides an influential example of the second.

12. On 'contrived collegiality' see Chap. 9 of Hargreaves' (1994) Changing Teachers, Changing Times: teachers' work and culture in the postmodern age.

\section{References}

Bourdieu, P., and J.C. Passeron. 1977. Reproduction in education, society and culture. London: Sage.

Bowles, S., and H. Gintis. 1976. Schooling in capitalist America. London: Routledge and Kegan Paul.

Hargreaves, A. 1994. Changing teachers, changing times: Teachers' work and culture in the postmodern age. London: Cassell. 
Hogan, P. 1995. The custody and courtship of experience: Western education in philosophical perspective. Dublin: Columba Press.

Hogan, P. 2009. The new significance of learning: Imagination's heartwork. London; New York: Routledge.

Murgatroyd, S., and C. Morgan. 1992. Total quality management and the school. Buckingham: Open University Press.

Oakeshott, M. 1962/1981. The voice of poetry in the conversation of mankind. In Rationalism in politics and other essays, 198. London \& New York: Methuen.

OECD. 2009. Education today: An OECD perspective. www.oecd.org/edu/educationtoday (accessed September 8, 2010).

Peters, R.S. 1966. Ethics and education. London: George Allen \& Unwin.

Plato. 2007. Republic, Trans. D. Lee. London: Penguin.

Rogers, C.R. 1970. Freedom to learn. Columbus, OH: Charles E. Merrill.

Woodhead, C. 2008. Chris Woodhead's part in a doomed act of education reform. The Sunday Times, August 3. http://www.timesonline.co.uk/tol/news/uk/education/ article4448440.ece. 